\title{
Recent changes in dry spell and extreme rainfall events in Ethiopia
}

\author{
YILMA SELESHI $^{1}$ \& PIERRE CAMBERLIN ${ }^{2}$ \\ ${ }^{1}$ Department of Civil Engineering, Faculty of Technology, Addis Ababa University, Ethiopia \\ ${ }^{2}$ Centre de Recherches de Climatologie, FRE 2740 CNRS/ Université de Bourgogne, Dijon, \\ France
}

Submitted to Theoretical and Applied Climatology, Revised version, $4^{\text {th }}$ February 2005 , with 4 figures

\footnotetext{
${ }^{1}$ Correspondence to: Department of Civil Engineering, Faculty of Technology, Addis Ababa University, POBox
} 385, Addis Ababa, Ethiopia. Tel.: 002519 222440; fax 002511 552601; e-mail: vilmash@ ceng.aau.edu.et 


\section{SUMMARY}

This paper assesses recent changes in extremes of seasonal rainfall in Ethiopia based on daily rainfall data for 11 key stations over the period 1965-2002. The seasons considered are Kiremt ('main rains', June - September) and Belg ('small rains', February/March - May). The Mann-Kendall and linear regression trend tests show decreasing trends in the Kiremt and the Belg extreme intensity and maximum consecutive 5-day rains over eastern, southwestern and southern parts of Ethiopia whereas no trends are found in the remaining part of Ethiopia. In general, no trends are found in the yearly maximum length of Kiremt and Belg dry spells (days with rainfall below $1 \mathrm{~mm}$ ) over Ethiopia.

KEY WORDS: DAILY RAINFALL, DRY SPELL, EXTREME EVENTS, TREND ANALYSIS, ETHIOPIA

\section{INTRODUCTION}

Extreme weather events in Ethiopia significantly affect the agro-socio-economic environment. Droughts in northern, southern and eastern Ethiopia cause great human sufferings and losses of life. Such consequences not only result from insufficient total rainfall amount, but also from long dry spells within the rainy season (for instance 1972 and 1987 recorded long dry spells of over 10 days). Occasionally floods and intense rainfall also cause devastating damage to crops and settlements. It is not, however, known whether the extreme events including drought are becoming more frequent and intense in the light of assumed global warming.

Changes in extreme precipitation have been reported in different parts of the world, but compared to other climate variables, available studies only provide a patchy image of such changes. Yet, it is a key question given that climate change projections suggest an increase in extreme events over many areas for the XXIst century (Cubasch et al., 2001). Significant increases in heavy precipitation rates have been observed in the USA (Frich, 
et al., 2002; Karl and Knight, 1998; Trenberth, 1998; Kunkel et al., 1999), Japan (Iwashima and Yamamoto, 1993), eastern and northeastern Australia (Suppiah and Hennessey, 1998; Plummer et al., 1999), South Africa (Mason et al., 1999), the UK in wintertime precipitation (Osborn et al., 2000) and northern and central Italy (Brunetti et $a l ., 2001 \mathrm{a}, \mathrm{b})$.

In contrast an analysis of rainfall data since 1910 by Haylock and Nicholls (2000) reveals a large decrease in total precipitation and related rain days in south-western Australia. Increases in heavy precipitation have also been documented even when mean total precipitation decreases for example in north Japan (Manton et al., 2001) and in Italy (Brunetti et al., 2001a).

In Niger, Shinoda et al. (1999) found that the droughts in the 1970s and 1980s were characterised primarily by a reduced frequency of heavy rainfall events (those exceeding $30 \mathrm{~mm} /$ day) rather than by a reduction in rainfall amount within heavy events. This is somehow consistent with a thorough analysis by Le Barbé et al. (2002), who found that in the Sahel the droughts were more related to a decrease in the number of events than to changes in the average rainfall per event. Other results for the SudanoSahel zone, including Nigeria and the Ethiopian Plateau (Tarhule and Woo, 1998 ; Easterling et al., 2000), suggest that there has been a decrease in the heaviest precipitation amounts, though they fail to indicate whether this is due to "less rainfall events" or to "less rain per event".

Seleshi and Zanke (2004) recently examined changes in rainfall totals and rainy days frequency in Ethiopia, over the period 1965-2002. No trend was found in central and northern Ethiopia, but a significant decline in annual and June-September rainfall was shown in the eastern, southern and southwestern stations, since about 1982. Trends in rainy days were generally less consistent. However, no analysis was carried out of possible changes in extreme rainfall, which may be distinct from those found in seasonal rainfall totals 
This paper assesses the recent changes in extreme seasonal rainfall as measured by 10 extreme rainfall indices over Ethiopia using daily rainfall data over the period 19652002 for 11 key stations, distributed in different climatic regions of Ethiopia. The organization of the paper is that section two presents the data used in the study and section three outlines the methods used, which are similar to those which Griffiths et al. (2003) applied to the South Pacific area. Finally, results and conclusions are given in sections four and five respectively.

\section{DATA}

Daily rainfall data for 43 stations having relatively good quality and long records $(>15$ years) over different climatic zones of Ethiopia were provided by the Ethiopian National Meteorological Services Agency. Close scrutiny of the data has shown that only 11 stations have daily rainfall data with less than $10 \%$ missing values in any given year. The period $1965-2002$ is taken as the common period having best data for all the 11 stations. The remaining 32 stations data were used for infilling missing data in the 11 stations selected.

The location and 10-day running mean daily rainfall plot of the eleven stations are shown in Figure 1. The 11 stations are grouped into 5 zones corresponding approximately to the various rainfall regimes of Ethiopia. The zones and station(s) included are: (i) Ethiopian Highlands: Addis Ababa (central), Debremarkos, Gondar (north-western), Kombolcha and Mekele (northern); (ii) north-east Rift Valley: Diredawa and Awash; (iii) eastern : Jijiga; (iv) southern: Negele, and (v) south-western: Gore and Jima.

In general, there exist three seasons in Ethiopia. The first is the main rainy season from June to September, the second is the dry season from October to December/January, and the third is the small rainy season from February/March to May. They are locally known as Kiremt, Bega and Belg respectively (NMSA, 1996). It is to be noted that the main rainy season at Negele is from March to May and the small rainy season is from 
October to December, the period from June to September being dry in southern and south-eastern Ethiopia.

\section{METHOD}

After digitizing the data, the daily time series from each station and for each year were plotted and visual examination carried out to identify any obvious outlier. Suspected outlier data were checked for typographical error, and then cross checked to verify that neighbouring stations had such high rainfall. In such a process no major anomaly was found. Monthly and annual time series were plotted and their values again checked for outliers. Missing daily rainfall values were filled using correlations of daily data with neighbouring stations. This procedure was mainly applied to 3 stations (Mekele, Jijiga and Negele) whose data showed discontinuities in 1990/91 caused by the political instability in Ethiopia.

Detection of changes in daily rainfall characteristics requires the time-series to be homogenous (e.g., Peterson et al., 1998). The series have thus been subjected to homogeneity tests, using the MASH technique developed at the Hungarian Meteorological Service (Szentimrey, 1999), and applied here on the seasonal rainfall totals. It is based on the construction of several difference series between the candidate and weighted reference series, but does not assume that the latter are homogenous. The difficulty for Ethiopia is to find enough references series in the vicinity of the candidate stations. The additional stations available are still quite far from the stations to be tested, and have incomplete series. Therefore, the results are merely indicative. Only two recurrent (i.e., consistently found in several difference series) break points were identified, both for Kiremt, in 1969-1970 at Gore and 1976-1977 at Jijiga. Given the distance between the reference series and these two stations, it is still uncertain that these shifts are not true climatic signals. However, the 1976-1977 shift at Jijiga coincides with the Ogaden war, which may have resulted in station relocation. Jijiga is located right on the margin of the summer (Kirmet) rainfall area (fig. 1), therefore any relocation may significantly affect the rainfall amount at this time of the year. Given the fact that there are no alternative stations in the corresponding regions, the two stations 
of Gore and Jijiga are kept in the analysis, but the results obtained are to be taken with caution.

Ten rainfall indices (five for Kiremt and five for Belg) were defined based on daily rainfall totals following Griffiths et al. (2003). Table 1 provides a list of these indices. The dry spell index calculates the maximum consecutive number of dry days recorded each year in Kiremt/Belg, and the 5-day index simply measures the greatest 5-day cumulative rainfall received per Kiremt/Belg season. Extreme intensity is an indicator of the typical size of an extreme rainfall event: it is the average of the highest 6 daily rainfalls (0.05* 122 or 120 days) in each year's Kiremt/Belg season.

Extreme frequency is a count of high rainfall events per Kiremt / Belg. $95^{\text {th }}$ percentiles are first determined on each year separately. As there are 122/120 days in Kiremt/Belg, the $95^{\text {th }}$ percentile corresponds to the $6^{\text {th }}$ highest rainfall. An 'extreme' rainfall is defined here as being equal to or above the $1965-2002$ mean $95^{\text {th }}$ percentiles. Extreme proportion measures how much of the total rain comes from extreme events: it is the proportion of seasonal rainfall that comes from the highest six rainfalls each season.

The 10 indices at the 11 stations were subjected to non-parametric Mann-Kendall test to detect trend over the period 1965-2002. Sneyers (1990) describes the use and computation of the test statistic, and only a brief description is given here. In the MannKendall test, for each element $x_{i}(i=1, \ldots, n)$ of the series, the number $n_{i}$ of lower elements $x_{j}\left(x_{j}<x_{i}\right)$ preceding it $(\mathrm{j}<\mathrm{i})$ is calculated and the test statistics $\mathrm{t}$ is given by

$$
t=\sum_{i} n_{i}
$$

In the absence of any trend (null hypothesis), $t$ is asymptotically normal, independently from the distribution function of the data, and

$$
u(t)=\frac{(t-\bar{t})}{\sqrt{\operatorname{var}(t)}}
$$


has a standard normal distribution, with $\bar{t}$ and $\operatorname{var}(t)$ given by

$$
\begin{gathered}
\bar{t}=\frac{n(n-1)}{4} \\
\operatorname{var}(t)=\frac{n(n-1) \cdot(2 n+5)}{72}
\end{gathered}
$$

The null hypothesis can, therefore, be rejected for high values of $|u(t)|$.

The sequential form of the Mann-Kendall test consists of the application of the test first to all the series starting with the first term and ending with the $i^{\text {th }}$ (progressive analysis), and then to those starting with the $i^{\text {th }}$ one and ending with the last term (regressive analysis). In the absence of any trend, the graphical representation of the direct $\left(u_{i}\right)$ and the backward $\left(u_{i}^{\prime}\right)$ series obtained with this method gives curves which overlap several times. In the case of a significant trend $\left(5 \%\right.$ level $\left.\left|\mathrm{u}_{\mathrm{i}}\right|>1.96\right)$, the intersection of the curves enables to detect approximately its time of occurrence. The slope of the linear trends was calculated by least square linear fitting of the extreme indices.

\section{RESULTS}

\subsection{Mean spatial and seasonal patterns}

Short Kiremt dry spell length (from a minimum of 3.3 days at Gore to 7.3 days at Addis Ababa) is seen over the western and central parts of Ethiopia (Table 2a). The northern and eastern parts of the country (Mekele, Kombolcha, Diredawa, Awash, Jijiga) have longer dry spells (from a minimum of 16.2 days at Jijiga to 20.3 days at Mekele) especially at the beginning of the main rainy season. This is partly because in these areas, i.e. along the eastern escarpment and in the Rift Valley region, the Kiremt rainy season starts late, June being a relatively dry month. It is also seen that the longer the Kiremt dry spell the higher the standard deviation. 
Belg maximum dry spell duration is generally longer as compared to Kiremt dry spell duration. Relatively short Belg dry spell length (from a minimum of 10.3 days at Jima to 18.9 days at Negele) is seen over the south-western and southern parts of Ethiopia (Table $2 \mathrm{~b}$ ). The northern, central and eastern parts of the country have longer dry spells (from a minimum of 19 days at Kombolcha to 31.1 days at Mekele). This variable shows a significant relationship (Pearson's linear correlation, 99\% confidence level) with total seasonal rainfall amounts (fig.2). However, for a given amount, quite large discrepancies among the stations exist in Belg dry spell lengths (e.g., for rainfall totals around 200 mm, Debre Markos has 17.6 days and Addis Ababa 31.1 days).

High Kiremt 5-day rainfall is observed in western Ethiopia (Gore $122 \mathrm{~mm}$ ) and northern Ethiopia (Debremarkos $105 \mathrm{~mm}$, Gondar $103 \mathrm{~mm}$ and Kombolcha $113 \mathrm{~mm}$ ), whereas low Kiremt 5-day is observed in eastern and southern Ethiopia. It is remarkable that the eastern-most stations (Diredawa and Jijiga) experience higher 5-day maximum rainfall in Belg than in Kiremt, though the latter is on the whole wetter. Similarly, though this variable is strongly related to total rainfall amounts (fig.2), the slopes of the linear regressions are very different for the two seasons. This reveals that the higher amounts of Kiremt are not due to more intense events but to more frequent rains. By contrast, Belg consists of a few wet spells recording large precipitation amounts, separated by long dry spells. For Kiremt, Mekele and Kombolcha again slightly demarcate, with 5day similar to other highland stations, but smaller seasonal rainfall amounts due to the relative dryness of June.

Extreme intensity exhibits basically the same pattern as 5-day (table 2 and fig. 2). Kiremt extreme intensity is high over the Ethiopian highlands and the western part of Ethiopia (more than $18.5 \mathrm{~mm}$, with the highest value at Gore, $33.7 \mathrm{~mm}$ ) as compared to the eastern part of the country (varying from $13.2 \mathrm{~mm}$ at Diredawa to $15.3 \mathrm{~mm}$ at Awash). High Belg extreme intensities are observed in the south and south western parts of Ethiopia. Again, the relationship with the seasonal rainfall amount differs between the two seasons (fig.2). In general, for a given seasonal amount, extreme intensities are comparatively higher in Belg than in Kiremt. For instance, a $400 \mathrm{~mm}$ seasonal total 
corresponds, based on the linear fit, to a $16.2 \mathrm{~mm}$ extreme intensity in Kiremt; in Belg, the same seasonal total corresponds to a $22.3 \mathrm{~mm}$ extreme intensity.

The highest Kiremt extreme frequency is observed at Jijiga, Diredawa and Negele (south-eastern or Rift Valley stations). This variable is poorly correlated to mean seasonal rainfall ( $\mathrm{r}=-0.14$ for Belg, -0.64 for Kiremt, the latter only being significant at the $95 \%$ c.1.). It is also more difficult to interpret than others, but one can consider that a lower frequency denote extreme events concentrated on a few years. Thus a higher frequency (i.e., close to 6 days, since the $95^{\text {th }}$ percentile corresponds to the 6 wettest days) indicates that the extreme events are scattered all across the years.

Extreme proportion shows spatial patterns which fairly well replicate those of mean seasonal rainfall amounts: drier areas (eastern and southern stations) have high values of extreme proportion (fig. 2). It is natural to think that the lower the seasonal rainfall, the more it is dependant upon extreme rainfall events. Belg therefore shows higher extreme proportion than Kiremt. At the northern station of Mekele nearly $85 \%$ of each year's Belg rainfall, on average, is coming from 6 storms $\left(95^{\text {th }}\right.$ percentile). During Kiremt, the highest extreme proportion is observed at Negele $(61.3 \pm 14 \%)$, followed by Diredawa $(51.8 \pm 8.2 \%)$; whereas the lowest extreme proportion is observed at the south western stations of Gore and Debremarkos (about $21 \pm 2 \%$ ).

\subsection{Changes in Kiremt extreme events}

The Mann-Kendall and linear regression trend test results show no trend in the length of the Kiremt dry spells, as measured by the dry spell index, over Ethiopia over the period 1965-2002 (Table 3). Moreover, no significant trend in the Kiremt 5-day rains is found over the Ethiopian Highlands although the general tendency is for increased 5-day rains. By contrast, a decreasing trend of the Kiremt 5-day rains was found in the eastern (Jijiga $-13 \mathrm{~mm} /$ decade i.e., $20 \%$ per decade, with the reservations made above about the homogeneity of the data) and southern (Negele $-11 \mathrm{~mm} /$ decade i.e., $10 \%$ per decade) parts of Ethiopia. The south-western station of Gore which is located in the wettest part 
of Ethiopia also exhibited a significant declining trend in the Kiremt 5-day rainfall (Gore $-19 \mathrm{~mm} /$ decade i.e., $15 \%$ per decade).

Changes in the extreme intensity $\left(95^{\text {th }}\right.$ percentile Kiremt) have slightly different spatial patterns over Ethiopia. A general tendency of increasing trend of extreme intensity (although not significant at 5\% level) was found over the Ethiopian Highlands. When the $99^{\text {th }}$ percentile is considered, the highest daily rainfall, an increasing trend of Kiremt extreme intensity was found over the $10-11^{\circ} \mathrm{N}$ latitudinal band of the Ethiopian Highlands (Kombolcha, Debremarkos). By contrast, a significant decreasing trend in Kiremt extreme intensity was found in the eastern (Jijiga $-3.1 \mathrm{~mm} /$ decade i.e., $20 \%$ per decade), southern (Negele $-2.3 \mathrm{~mm} /$ decade i.e., 16\% per decade) and south western (Gore $-4.8 \mathrm{~mm} /$ decade i.e., $14 \%$ per decade) parts of Ethiopia, coincident with the decreasing trend in Kiremt 5-day rains (Figure 3).

Kiremt extreme frequency, measuring the Kiremt frequency of daily rainfall exceeding the 1965-2002 mean $95^{\text {th }}$ percentile, shows a significant decline in eastern (Jijiga -0.6 days/decade i.e., $11 \%$ per decade), southern (Negele -0.6 days / decade i.e., $12 \%$ per decade) and south western (Gore -0.6 days/decade i.e., $27 \%$ per decade) Ethiopia. The percentage of Kiremt total rainfall from events greater than or equal to the $95^{\text {th }}$ percentile, Kiremt extreme proportion, shows no trend over Ethiopia.

These results should be compared to an analysis of total Kiremt rainfall variations (Seleshi and Zanke, 2004). For the same period (1965-2002), no trend was found over most of Ethiopia, except for the eastern, southern and south-western stations, displaying a similar decline as for 5-day, extreme intensity and extreme frequency. Figure 4 confirms that interannual rainfall variations during Kiremt are strongly correlated to those of extreme events. The correlations between total seasonal rainfall variations and each of the variables are computed for all the 11 stations, and displayed as box-plots. Dry spell lengths are generally not significantly correlated to total rainfall; the same applies to extreme frequency and extreme proportion.

\subsection{Changes in Belg extreme events}


Belg rains have significant economic importance for the country because the 'long cycle (March -October) high yield' crops such as sorghum and maize are planted in March. On average these crops constitute about $50 \%$ of the national cereal production, provided that adequate Kiremt rains subsequently fall.

The Mann-Kendall and linear regression trend test results show a decreasing trend in Belg dry spell over eastern Rift Valley stations (at Awash, dry spell declined by 2.8 days/decade i.e., $12 \%$ per decade; at Diredawa 5.4 days/decade i.e., $22 \%$ per decade). In general the Belg 5-day rains show no trend over Ethiopia except at Gore with a decline of $13 \mathrm{~mm} /$ decade (i.e., 12\% per decade). Belg extreme intensity has declined in the southern (Negele $-3.8 \mathrm{~mm} /$ decade i.e., 15\% per decade) and south western (Gore -2.7 $\mathrm{mm} /$ decade i.e., $16 \%$ per decade) parts of Ethiopia. Like Belg extreme intensity, Belg extreme frequency has declined in southern and south-western Ethiopia (Negele and Gore both showing a decrease of one day per decade, i.e. about 20\%). Belg extreme proportion has declined in the eastern Rift Valley stations (Diredawa - 3.9\% / decade i. e., $6 \%$ per decade; and Awash $-4.9 \%$ /decade i.e., $7 \%$ per decade).

On the whole, there is no uniform pattern of either increased or decreased extreme rainfall events over Ethiopia in Belg. Only Gore and Negele show consistent decreasing trends in extreme wet events. Rift Valley stations tend to get shorter dry spells, while the proportion of extreme wet events is decreasing. This is indicative of more wet, low intensity rainfall days, scattered across the season. It is confirmed by the significant increasing trend in Belg rainy days found for the same stations in Seleshi and Zanke (2004).

Total Belg rainfall variations are strongly correlated to 5-day and extreme intensity (figure 4) ; the same feature was found during Kiremt, though Belg correlations tend to be higher. In addition, the seasonal amounts are strongly correlated to extreme frequency and proportion. This greater sensitivity of Belg seasonal rainfall amounts to variations in the number and intensity of the wettest events has already been suggested in section 4.1 . 


\section{CONCLUSIONS}

It is found that extreme intensity in Kiremt (main rainy season) has two distinct trends over Ethiopia in the period 1965-2002 :

(i) A weak increasing trend over the $10-11^{\circ}$ North band of the Ethiopian Highlands (when $99^{\text {th }}$ percentile is considered), and no trend over the remaining Ethiopian Highlands, as opposed to Easterling et al. (2000)'s findings that extreme intensity is decreasing over the Ethiopian Highlands. This discrepancy may come from the fact that quite different periods are used in the two studies. Easterling et al. analysed trends between 1951 and 1987, which coincides fairly well with the period of decreased rainfall across the sudano-sahelian belt, including Ethiopia. The present study starts in 1965 , thus excluding much of the wet Kiremt seasons of the 1950s and 1960s.

(ii) A decreasing trend in the Kiremt extreme intensity however was found in the eastern, southern and part of south-western Ethiopia coincident with a decreasing trend in Kiremt 5-day rains and Kiremt total rainfall.

The study also revealed that there is no recent trend in the length of Kiremt dry spell in Ethiopia. The percentage of Kiremt total rainfall from events greater than or equal to the $95^{\text {th }}$ percentile, Kiremt extreme proportion, shows also no trend over Ethiopia.

Compared to Kiremt, Belg contains much more dry days, separating a few quite intense wet events ; therefore seasonal rainfall amounts strongly depend on variations in the frequency and intensity of these wet spells. Changes in Belg characteristics are highly localized. Most of the Ethiopian Highlands remain free of any trend. Enhanced Belg rains have been observed over the eastern Rift Valley stations of Awash and Diredawa. In general the Belg 5-day index shows no trend over Ethiopia except for a decreasing trend at Gore. The Belg extreme intensity, however has declined in the southern and south western Ethiopia where the Kiremt extreme intensity has also declined. 
Note that caution should be exerted in the generalisation of these results. Apart from reservations about data homogeneity for a few stations (especially Jijiga), this is a consequence of the small number of stations available compared to the huge size of the area under investigation.

\section{ACKNOWLEDGMENTS}

Daily rainfall data for 43 stations were kindly provided by Ethiopian National Meteorological Services Agency. 


\section{REFERENCES}

Brunetti M, Colacino M, Maugeri M, Nanni T. (2001a) Trends in the daily intensity of precipitation in Italy from 1951 to 1996. International Journal of Climatology 21: 299-316.

Brunetti M, Maugeri M, Nanni T. (2001b) Changes in daily precipitation distribution and in extreme events in the eastern alpine region. International Journal of Climatology 21: 861-871.

Cubasch U., Meehl G.A., Boer G.J., Stouffer R.J., Dix M., Noda A., Senior C.A., Raper S., Yap K.S. (2001) Projections of future climate change. In : Climate Change 2001 : the scientific basis. Contribution of Working Group I to the Third Assessment Report of the IPCC [Houghton J.T., Ding Y., Griggs D.J., Noguer M., van der Linden P.J., Dai X., Maskell K., Johnson C.A., Eds]. Cambridge Univ. Pr., 525-582.

Easterling DR, Evans JL, Groisman PYa, Karl TR, Kunkel KE, Ambenje P. (2000) Observed variability and trends in extreme climate events. Bull. Am. Met. Soc. 81: 417-425.

Frich P, Alexander LV, Della-Marta P, Gleason B, Haylock M, Klein Tank, AMG, Peterson T. (2002) Observed coherent changes in climatic extremes during the second half of the twentieth century. Climate Research, 19: 193-212.

Griffiths GM, Salinger MJ, Leleu I. (2003) Trends in extreme daily rainfall across the South Pacific and relationship to the South Pacific Convergence Zone. International Journal of Climatology 23: 847-869.

Haylock M, Nicholls N. (2000) Trends in extreme rainfall indices for an updated high quality data set for Australia, 1910-1998. International Journal of Climatology 20: 1533-1541.

Iwashima T, Yamamoto R. (1993) A statistical analysis of the extreme events: long-term trend of heavy daily precipitation. Journal of the Meteorological Society of Japan 71: 637-640.

Karl TR, Knight RW. (1998) Secular trends of precipitation amount frequency and intensity in the United States. Bulletin of the American Meteorological Society 79: 231-241.

Kunkel KE, Pielker Jr RA, Changnon SA. (1999) Temporal fluctuation in winter and climate extremes that cause economic and human health impact: a review. International Journal of Climatology 19: 10771098.

Le Barbé L, Lebel T, Tapsoba D (2002) Rainfall variability in West Africa during the years 1950-90. Journal of Climate, 15, 2: 187-202 
Manton, MJ, Della-Marta PM, Haylock MR, Hennessy KJ, Nicholls N, Chambers LE, Collins DA, Daw G, Finet A, Gunawan D, Inape K, Isobe H, Kestin TS, Lafale P, Leyu CH, Lwin T, Maitrepierre L, Ouprasitwong N, Page CM, Pahalad J, Plummer N, Salinger MJ, Suppiah R, Tran VL, Trewin B, Tibig I, Yee D. (2001) Trends in extreme daily rainfall and temperature in Southeast Asia and the South Pacific: 1961-1998. International Journal of Climatology 21: 269-284.

Mason SJ, Waylen PR, Mimmack GM, Rajaratnam B, Harrison JM. (1999) Changes in extreme rainfall events in South Africa. Climate Change 41: 249-257.

NMSA (1996) Climatic and Agroclimatic resources of Ethiopia. NMSA Meteorological Research Report Series. V1, No. 1, Addis Ababa, $137 \mathrm{p}$.

Osborn TJ, Hulme M, Jones PD, Basnett TA. (2000) Observed trends in the daily intensity of United Kingdom precipitation. International Journal of Climatology 20: 347-364.

Peterson TC, Easterling DR, Karl TR, Groisman P, Nicholls N, Plummer N, Torok S, Auer I, Boehm R, Gullett D, Vincent L, Heino R, Tuomenvirta H, Mestre O, Szentimrey T, Salinger MJ, Forland EJ, Hanssen-Bauer I, Alexandersson H, Jones PD, Parker DE (1998) Homegeneity adjustments of in situ climate data: A Review. International Journal of Climatology 18: 1493-1517.

Plummer NJ, Salinger A, Nicholls N, Suppiah R, Hennessy K, Leighton RM, Trewin B, Page CM, Lough JM. (1999) Changes in climate extremes over the Australian region and New Zealand during the twentieth century. Climate Change 42: 183-202.

Seleshi Y., Zanke U. (2004) Recent changes in rainfall and rainy days in Ethiopia. International Journal of Climatology 24: 973-983.

Shinoda M, Okatani T, Saloum M. (1999) Diurnal variations of rainfall over Niger in the West African Sahel: A comparison between wet and drought years. International Journal of Climatology 19: 81-94.

Sneyers R. (1990) On the statistical analysis of series of observation. WMO Technical Note NO. 143, Geneva.

Suppiah R, Hennessey KJ. (1998) Trends in total rainfall, heavy rain events and numbers of dry days in Australia. International Journal of Climatology 18: 1141-1164.

Szentimrey T. (1999) Multiple Analysis of Series for Homogenization (MASH). Proceedings of the Second Seminar for Homogenization of Surface Climatological Data, Budapest, Hungary. WMO, TD $n^{\circ} 962,27-46$ 
Recent changes in dry spell and extreme rainfall events in Ethiopia

Tarhule A, Woo M. (1998) Changes in rainfall characteristics in northern Nigeria. International Journal of Climatology 18: 1261-1271.

Trenberth KE. (1998) Atmospheric moisture residence times and cycling: implications for rainfall rates with climate change. Climate Change 39: 667-694. 
Table I. Kiremt / Belg extreme rainfall indices; the index units are in parentheses

\begin{tabular}{|c|c|c|}
\hline & Measurement & Index name \\
\hline 1 & $\begin{array}{l}\text { Kiremt/Belg maximum number of consecutive days with rainfall } \\
\text { less than } 1 \mathrm{~mm} \text { (days) }\end{array}$ & Kiremt/Belg Dry spell \\
\hline 2 & The greatest consecutive Kiremt/Belg 5 day rainfall total (mm) & Kiremt/Belg 5-day \\
\hline 3 & $\begin{array}{l}\text { Average intensity of events greater than or equal to the } 95^{\text {th }} \\
\text { percentile, i.e. the six wettest event in Kiremt/Belg }(\mathrm{mm})\end{array}$ & Kiremt/Belg Extreme Intensity \\
\hline 4 & $\begin{array}{l}\text { Kiremt/Belg frequency of daily rainfall exceeding the } 1965-2002 \\
\text { mean } 95^{\text {th }} \text { percentile (days). }\end{array}$ & $\begin{array}{l}\text { Kiremt/Belg } \\
\text { Frequency }\end{array}$ \\
\hline 5 & $\begin{array}{l}\text { Percentage of Kiremt/Belg total rainfall from events greater than } \\
\text { or equal to the } 95^{\text {th }} \text { percentile }(\%) \text {. }\end{array}$ & $\begin{array}{l}\text { Kiremt/Belg } \\
\text { proportion }\end{array}$ \\
\hline
\end{tabular}


Table 2a. Some statistical characteristics of Kiremt (June-September) extreme rainfall indices over Ethiopia estimated over the period 1965-2002.

\begin{tabular}{|c|c|c|c|c|c|c|c|c|c|c|c|}
\hline \multirow[b]{2}{*}{ Zone } & \multirow[b]{2}{*}{ Stations } & \multicolumn{2}{|c|}{ Dry spell (day) } & \multicolumn{2}{|c|}{ 5-day (mm) } & \multicolumn{2}{|c|}{$\begin{array}{l}\text { Extreme } \\
\text { intensity }(\mathrm{mm})\end{array}$} & \multicolumn{2}{|c|}{$\begin{array}{l}\text { Extreme } \\
\text { Frequency } \\
\text { (day) }\end{array}$} & \multicolumn{2}{|c|}{$\begin{array}{l}\text { Extreme } \\
\text { Proportion } \\
(\%)\end{array}$} \\
\hline & & Mean & STD & Mean & STD & Mean & STD & Mean & STD & Mean & STD \\
\hline \multirow{5}{*}{$\begin{array}{l}\text { Ethiopian } \\
\text { Highlands }\end{array}$} & Addis Ababa & 7.3 & 2.7 & 85 & 18 & 21.2 & 2.8 & 2.9 & 1.7 & 24.2 & 3.3 \\
\hline & Debremarkos & 5.2 & 2.5 & 105 & 20 & 25.0 & 2.9 & 1.0 & 1.0 & 21.2 & 2.0 \\
\hline & Gondar & 7.0 & 2.4 & 103 & 26 & 25.8 & 6.6 & 0.8 & 1.0 & 24.9 & 2.8 \\
\hline & Kombolcha & 18.7 & 7.4 & 113 & 28 & 23.9 & 4.9 & 2.1 & 1.7 & 32.9 & 5.5 \\
\hline & Mekele & 20.3 & 6.7 & 92 & 30 & 18.5 & 4.9 & 1.0 & 1.4 & 38.6 & 6.2 \\
\hline \multirow{2}{*}{$\begin{array}{l}\text { North East } \\
\text { Rift Valley }\end{array}$} & Diredawa & 19.3 & 8.1 & 62 & 25 & 13.2 & 5.4 & 5.8 & 3.3 & 51.8 & 8.2 \\
\hline & Awash & 16.8 & 7.8 & 73 & 27 & 15.3 & 4.0 & 3.4 & 2.0 & 47.2 & 7.0 \\
\hline Eastern & Jijiga & 16.2 & 6.0 & 64 & 28 & 15.1 & 6.2 & 5.6 & 3.0 & 48.0 & 7.8 \\
\hline Southern & Negele & 35.4 & 15.3 & 80 & 37 & 14.5 & 6.6 & 5.2 & 2.9 & 61.3 & 14.4 \\
\hline South & Gore & 3.3 & 1.6 & 122 & 34 & 33.7 & 9.5 & 2.2 & 1.8 & 21.3 & 2.4 \\
\hline western & Jima & 4.8 & 1.7 & 92 & 16 & 24.1 & 3.8 & 4.0 & 4.2 & 48.0 & 7.8 \\
\hline
\end{tabular}

Table 2b. The same as Table 2a but for Belg (February-May) extreme rainfall indices

\begin{tabular}{|c|c|c|c|c|c|c|c|c|c|c|c|}
\hline \multirow[b]{2}{*}{ Zone } & \multirow[b]{2}{*}{ Stations } & \multicolumn{2}{|c|}{ Dry spell (day) } & \multicolumn{2}{|c|}{ 5-day (mm) } & \multicolumn{2}{|c|}{$\begin{array}{l}\text { Extreme } \\
\text { intensity }(\mathrm{mm})\end{array}$} & \multicolumn{2}{|c|}{$\begin{array}{l}\text { Extreme } \\
\text { Frequency } \\
\text { (day) }\end{array}$} & \multicolumn{2}{|c|}{$\begin{array}{l}\text { Extreme } \\
\text { Proportion } \\
(\%)\end{array}$} \\
\hline & & Mean & STD & Mean & STD & Mean & STD & Mean & STD & Mean & STD \\
\hline \multirow{5}{*}{$\begin{array}{l}\text { Ethiopian } \\
\text { Highlands }\end{array}$} & Addis Ababa & 31.1 & 11.3 & 74 & 29 & 14.8 & 6.1 & 4.9 & 2.4 & 62.6 & 11.1 \\
\hline & Debremarkos & 17.6 & 8.9 & 57 & 21 & 11.5 & 4.5 & 5.3 & 3.1 & 53.8 & 10.6 \\
\hline & Gondar & 26.4 & 12.4 & 47 & 20 & 9.2 & 4.7 & 4.8 & 2.8 & 66.3 & 13.2 \\
\hline & Kombolcha & 19.0 & 6.6 & 64 & 22 & 14.4 & 5.0 & 5.1 & 2.5 & 59.7 & 12.4 \\
\hline & Mekele & 31.1 & 11.3 & 36 & 24 & 5.8 & 4.3 & 5.2 & 3.0 & 84.6 & 13.5 \\
\hline North East & Diredawa & 24.0 & 11.6 & 70 & 33 & 14.4 & 7.0 & 5.2 & 3.1 & 66.3 & 12.1 \\
\hline Rift Valley & Awash & 23.0 & 9.0 & 58 & 27 & 10.7 & 5.4 & 4.8 & 2.3 & 72.8 & 12.7 \\
\hline Eastern & Jijiga & 22.3 & 11.7 & 77 & 33 & 16.6 & 7.3 & 4.9 & 3.0 & 63.4 & 12.0 \\
\hline Southern & Negele & 18.9 & 8.7 & 110 & 31 & 25.5 & 8.9 & 5.0 & 2.8 & 52.2 & 8.7 \\
\hline South & Gore & 16.4 & 9.0 & 97 & 27 & 24.0 & 6.5 & 4.7 & 2.6 & 42.7 & 6.1 \\
\hline western & Jima & 10.3 & 3.9 & 82 & 23 & 20.5 & 4.4 & 5.3 & 4.5 & 39.5 & 11.2 \\
\hline
\end{tabular}


Table 3. Linear trend per decade (LT) in Kiremt (June-September) dry spell, 5-day, extreme intensity, extreme frequency and extreme proportion over the period 1965-2002. The Mann-Kendall (MK) trend test result is indicated as NST for No Significant Trend, IST for Increasing Significant Trend and DST for Decreasing Significant Trend at 95\% level. Statistically significant linear trends at the $95 \%$ level are shown in *. For Negele station the October-December season is considered.

\begin{tabular}{|c|c|c|c|c|c|c|}
\hline & & Dry spell (day) & 5-day (mm) & $\begin{array}{c}\text { Extreme } \\
\text { Intensity }(\mathrm{mm})\end{array}$ & $\begin{array}{c}\text { Extreme } \\
\text { Frequency (day) }\end{array}$ & $\begin{array}{l}\text { Extreme } \\
\text { Proportion } \\
(\%)\end{array}$ \\
\hline Zone & Stations & LT MK & LT MK & LT MK & $\mathrm{LT} \mathrm{MK}$ & LT MK \\
\hline \multirow{5}{*}{$\begin{array}{l}\text { Ethiopian } \\
\text { Highlands }\end{array}$} & Addis Ababa & $\sim 0 \mathrm{NST}$ & -2.0 NST & $+0.2 \mathrm{NST}$ & $\sim 0 \quad \mathrm{NST}$ & $-0.5 \mathrm{NST}$ \\
\hline & Debremarkos & $\sim 0 \mathrm{NST}$ & $+2.5 \mathrm{NST}$ & $+0.1 \mathrm{NST}$ & $\sim 0 \quad \mathrm{NST}$ & +0.5 NST \\
\hline & Gondar & $\sim 0 \mathrm{NST}$ & $+3.6 \mathrm{NST}$ & $+0.1 \mathrm{NST}$ & $\sim 0 \quad \mathrm{NST}$ & -0.5 NST \\
\hline & Kombolcha & $\sim 1.4 \mathrm{NST}$ & $+5.5 \mathrm{NST}$ & $+0.7 \mathrm{NST}$ & $+0.1 \mathrm{NST}$ & $+0.1 \mathrm{NST}$ \\
\hline & Mekele & $\sim 0 \mathrm{NST}$ & $\sim 0$ NST. & $\sim 0$ NST & $\sim 0$ NST & +0.4 NST \\
\hline \multirow{2}{*}{$\begin{array}{l}\text { North East } \\
\text { Rift Valley }\end{array}$} & Diredawa & $\sim 0 \mathrm{NST}$ & $\sim 0 \mathrm{NST}$ & $+1.1 \mathrm{NST}$ & $+0.5 \mathrm{NST}$ & $-2.0 \mathrm{NST}$ \\
\hline & Awash & $\sim 0 \quad \mathrm{NST}$ & $+2.1 \mathrm{NST}$ & $+0.1 \mathrm{NST}$ & $+0.1 \mathrm{NST}$ & -0.15 NST \\
\hline Eastern & Jijiga & $\sim 0$ NST & $-12.9^{*}$ DST & $-3.1^{*}$ DST & $-0.6^{*}$ DST & +1.4 NST \\
\hline Southern & Negele & $\sim 0$ NST & $-11.3^{*}$ DST & $-2.3^{*}$ DST & $-0.6^{*}$ DST & $-0.3 \mathrm{NST}$ \\
\hline South & Gore & $\sim 0$ NST & $-19.1^{*}$ DST & $-4.8^{*}$ DST & $-0.6^{*}$ DST & $+0.3 \mathrm{NST}$ \\
\hline Western & Jima & $\sim 0$ NST & $+4.0 \mathrm{NST}$ & +0.6 NST & $-0.1 \mathrm{NST}$ & +0.3 NST \\
\hline
\end{tabular}


Table 4. Linear trend per decade (LT) in Belg (February-May) dry spell, 5-day, extreme intensity, extreme frequency and extreme proportion over the period 1965-2002. The Mann-Kendall (MK) trend test result is indicated as NST for No Significant Trend, IST for Increasing Significant Trend and DST for Decreasing Significant Trend at $95 \%$ level. Statistically significant linear trends at the $95 \%$ level are shown as *.

\begin{tabular}{|c|c|c|c|c|c|c|}
\hline & & Dry spell (day) & 5-day (mm) & $\begin{array}{c}\text { Extreme } \\
\text { Intensity }(\mathrm{mm})\end{array}$ & $\begin{array}{c}\text { Extreme } \\
\text { Frequency (day) }\end{array}$ & $\begin{array}{c}\text { Extreme } \\
\text { Proportion } \\
(\%)\end{array}$ \\
\hline Zone & Stations & LT MK & LT $\mathrm{MK}$ & LT MK & LT MK & LT MK \\
\hline \multirow{5}{*}{$\begin{array}{l}\text { Ethiopian } \\
\text { Highlands }\end{array}$} & Addis Ababa & $\sim 0 \quad \mathrm{NST}$ & -3.7 NST & $\sim 0$ NST & $-0.1 \mathrm{NST}$ & $-1.2 \mathrm{NST}$ \\
\hline & Debremarkos & $-1.9 \mathrm{NST}$ & $+3.6 \mathrm{NST}$ & +0.7 NST & +0.6 IST & $-0.3 \mathrm{NST}$ \\
\hline & Gondar & $\sim 0 \mathrm{NST}$ & $\sim 0 \mathrm{NST}$ & $-0.6 \mathrm{NST}$ & +0.2 NST & -0.2 NST \\
\hline & Kombolcha & $-1.3 \mathrm{NST}$ & $-3.3 \mathrm{NST}$ & $-0.2 \mathrm{NST}$ & $\sim 0 \quad \mathrm{NST}$ & $-0.5 \mathrm{NST}$ \\
\hline & Mekele & $\sim 0 \mathrm{NST}$ & $-1.4 \mathrm{NST}$ & $-0.2 \mathrm{NST}$ & $\sim 0 \mathrm{NST}$ & $-0.2 \mathrm{NST}$ \\
\hline North East & Diredawa & $-5.4^{*}$ DST & $+5.3 \mathrm{NST}$ & +1.5 IST & +0.3 IST & $-3.9^{*}$ DST \\
\hline Rift Valley & Awash & $-2.8^{*} \quad$ DST & $\sim 0 \mathrm{NST}$ & $-1.2 \mathrm{NST}$ & $+0.2 \mathrm{NST}$ & $-4.9^{*}$ DST \\
\hline Eastern & Jijiga & $-2.2 \mathrm{NST}$ & $-4.9 \mathrm{NST}$ & $-0.9 \mathrm{NST}$ & -0.6 NST & $-1.7 \mathrm{NST}$ \\
\hline Southern & Negele & $\sim 0$ NST & -9.9 NST & $-3.8^{*}$ DST & $-1.0^{*}$ DST & $+0.6 \mathrm{NST}$ \\
\hline South & Gore & -1.6 NST & $-13.0^{*}$ DST & $-2.7^{*}$ DST & $-1.0^{*}$ DST & $-1.2 \mathrm{NST}$ \\
\hline Western & Jima & $-1.0 \mathrm{NST}$ & +3.8 NST & $+0.3 \mathrm{NST}$ & $\sim 0 \quad$ NST & -1.3 NST \\
\hline
\end{tabular}




\section{Figure captions}

Figure 1 : Location of the 11 stations used in the study, and 10-day running mean rainfall (mm/day). Also the mean (top) and standard deviation (below), in $\mathrm{mm}$, of the station annual rainfall estimated over the period $1965-2002$ are shown. The $1^{\text {st }} 10$-day average value is plotted at Jan 1 . The thick dotted line delineates the region to the southeast of which June-September is dry.

Figure 2 : Relationships between mean (1965-2002) seasonal rainfall amounts and mean extreme rainfall indices, for Belg (circles) and Kiremt (pluses and bold names) Single (double) stars accompanying the correlation coefficients denote significant values at the $95 \%$ (99\%) confidence level. Linear fits for 5-day maximum rainfall and extreme intensity, for Belg and Kiremt separately, are shown as solid and dashed lines, respectively. Note that Negele was not used in the computation of the Kiremt linear regressions, since the rainy season there occurs in October-December.

Figure 3 : Progressive application of the Mann-Kendall test to the Kiremt extreme intensity time-series $\left(\mathrm{Z}\right.$, bold line, standardised). $\quad U_{i}-\mathrm{u}(\mathrm{t})$ : solid line; $U_{i}^{\prime}=\mathrm{u}^{\prime}(\mathrm{t})$ : dashed line. A significant decrease of Kiremt extreme intensity is observed at Jijiga (A, eastern Ethiopia), Gore (B, south western) and Negele (C, southern - OctoberDecember rainy season).

Figure 4 : Box-plots of the Pearson's linear correlations between the interannual variability (1965-2002) of seasonal rainfall totals and the extreme rainfall indices at each station, for Belg (left) and Kiremt (right). Bottom and top of each box correspond to the lower and upper quartiles, respectively. The inner line shows the median value of the 11 stations. The 'whiskers' encompass all the 11 correlations, except outliers which are shown as pluses. Horizontal dashed lines : 95\% confidence levels for Pearson's correlation. 
Figure 1. Location of the 11 stations used in the study, and 10-day running mean rainfall ( $\mathrm{mm} /$ day). Also the mean (top) and standard deviation (below), in $\mathrm{mm}$, of the station annual rainfall estimated over the period 1965-2002 are shown. The $1^{\text {st }} 10$-day average value is plotted at Jan 1 . The thick dotted line delineates the region to the south-east of which June-September is dry.

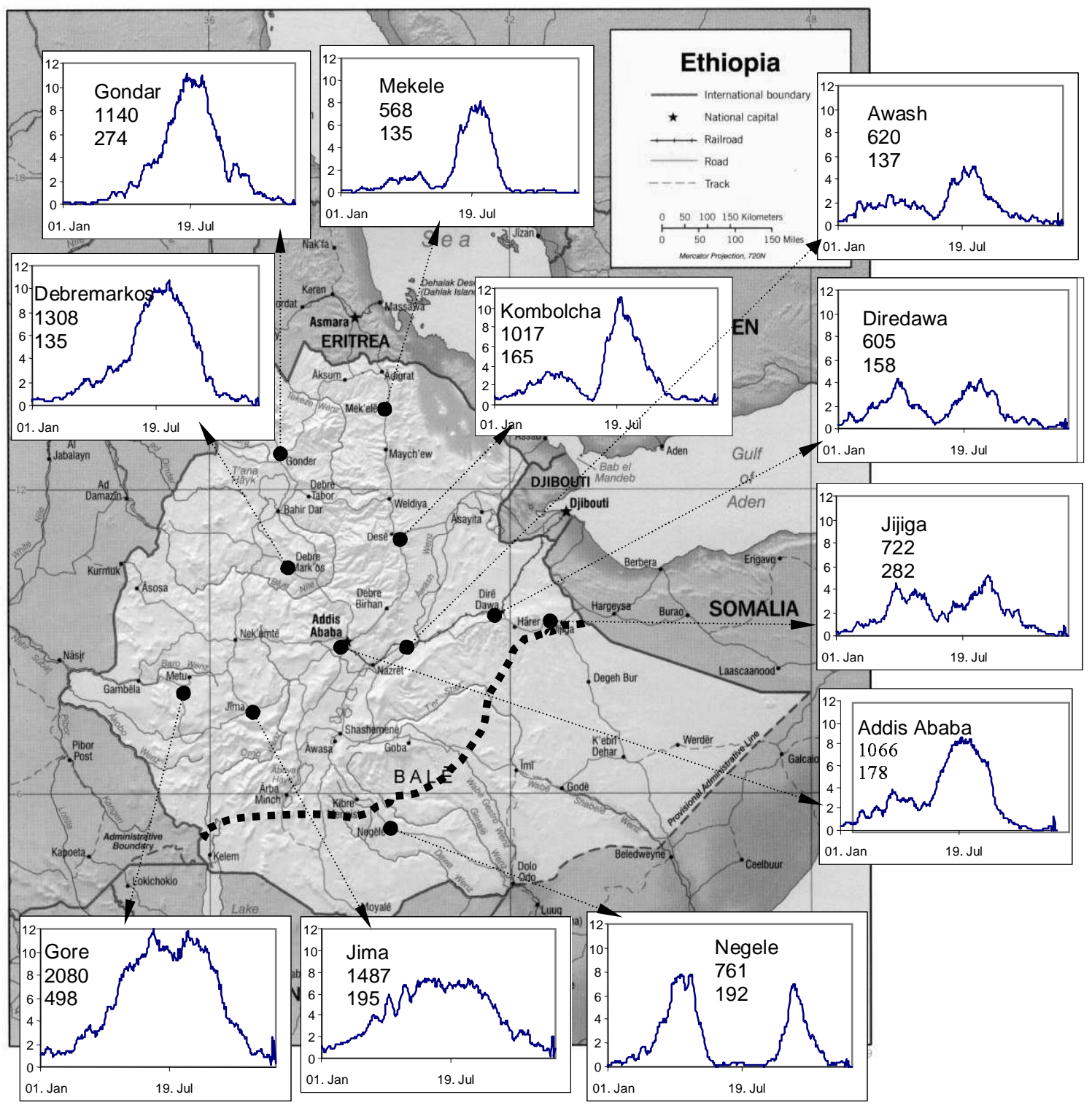


Figure 2 : Relationships between mean (1965-2002) seasonal rainfall amounts and mean extreme rainfall indices, for Belg (circles) and Kiremt (pluses and bold names) Single (double) stars accompanying the correlation coefficients denote significant values at the $95 \%(99 \%)$ confidence level. Linear fits for 5-day maximum rainfall and extreme intensity, for Belg and Kiremt separately, are shown as solid and dashed lines, respectively. Note that Negele was not used in the computation of the Kiremt linear regressions, since the rainy season there occurs in October-December.
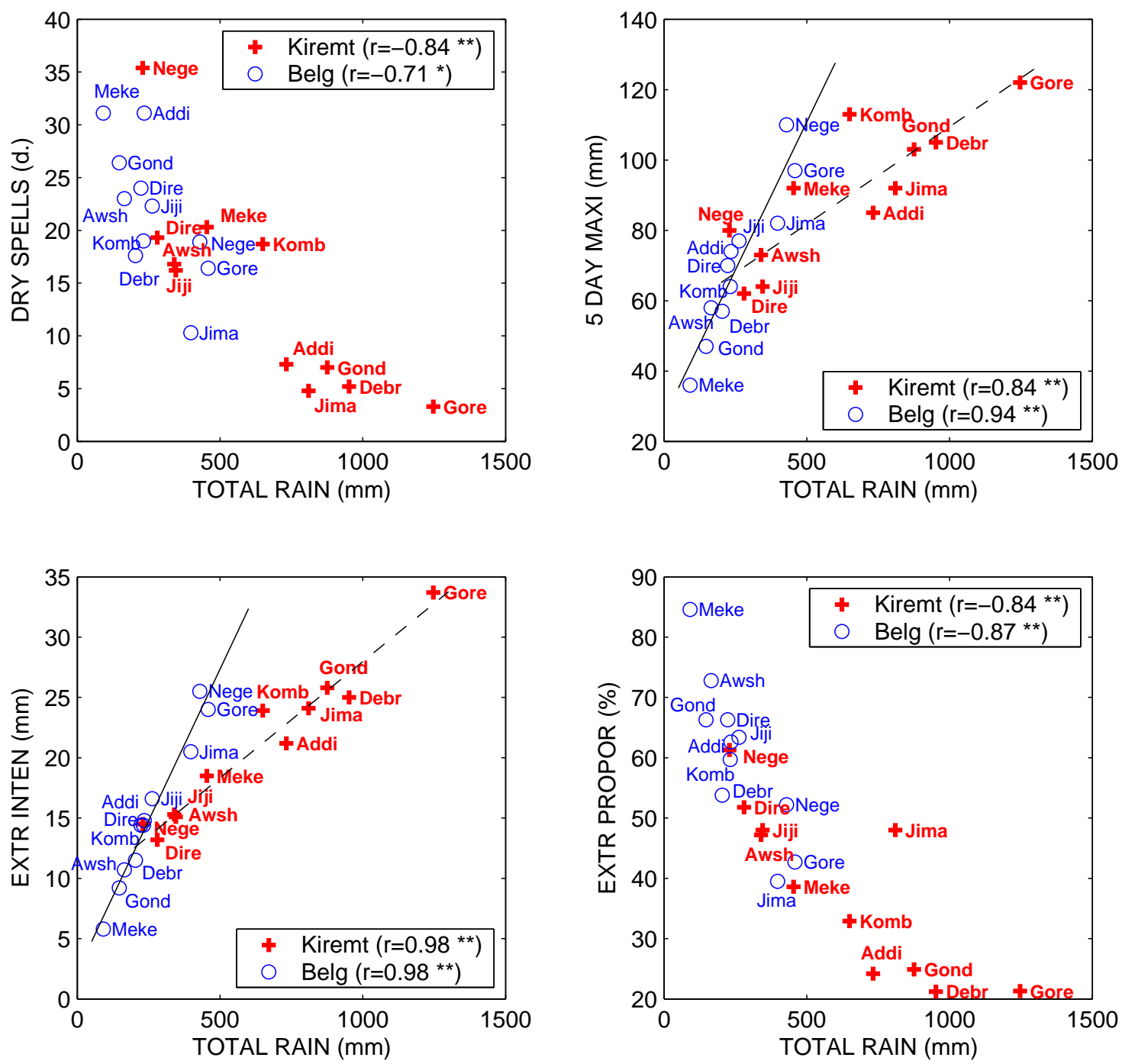
Figure 3 : Progressive application of the Mann-Kendall test to the Kiremt extreme intensity time-series $\left(\mathrm{Z}\right.$, bold line, standardised). $U_{i}-\mathrm{u}(\mathrm{t})$ : solid line; $U_{i}^{\prime}=\mathrm{u}^{\prime}(\mathrm{t})$ : dashed line. A significant decrease of Kiremt extreme intensity is observed at Jijiga (A, eastern Ethiopia), Gore (B, south western) and Negele (C, southern - OctoberDecember rainy season).
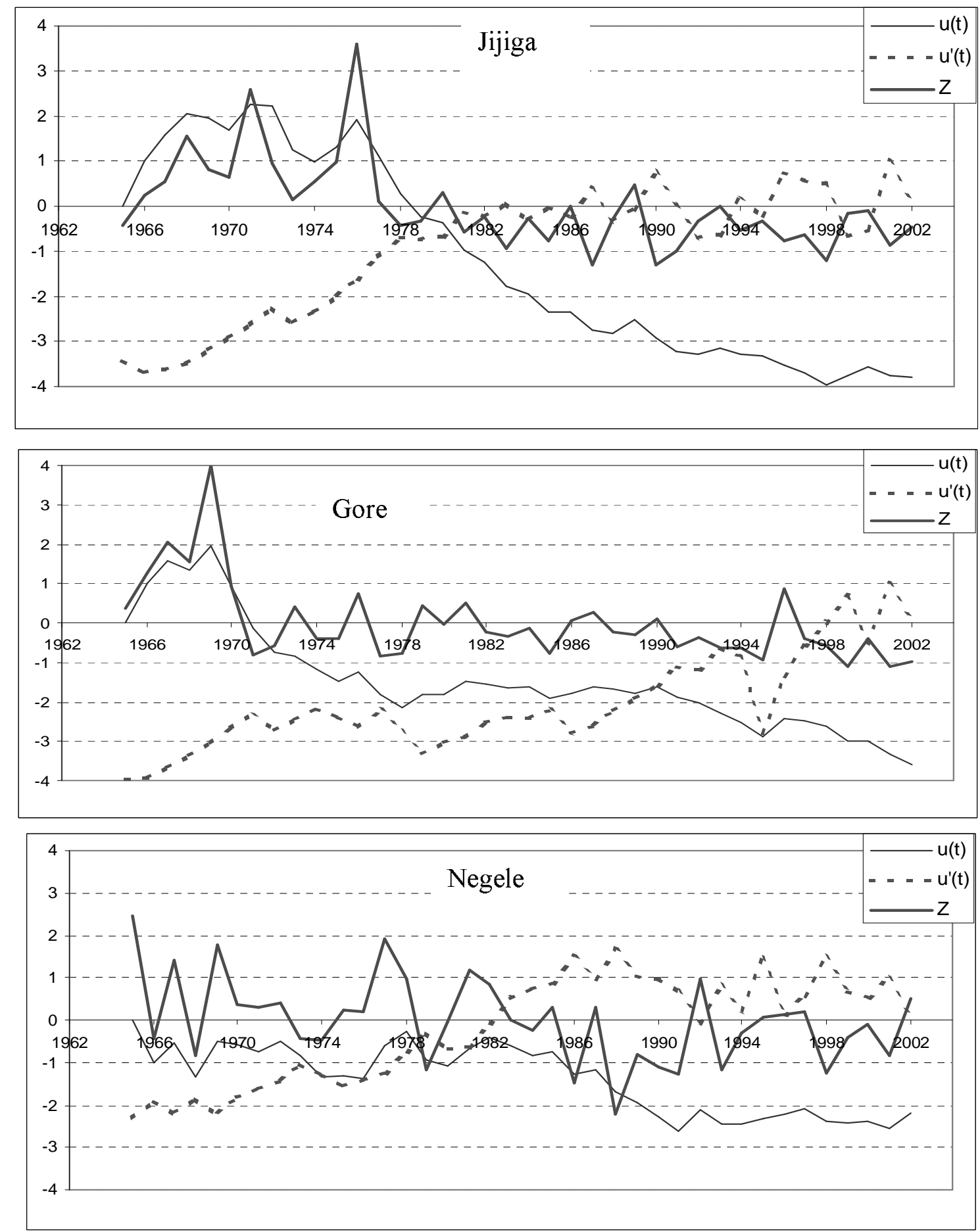
Figure 4 : Box-plots of the Pearson's linear correlations between the interannual variability (1965-2002) of seasonal rainfall totals and the extreme rainfall indices at each station, for Belg (left) and Kiremt (right). Bottom and top of each box correspond to the lower and upper quartiles, respectively. The inner line shows the median value of the 11 stations. The 'whiskers' encompass all the 11 correlations, except outliers which are shown as pluses. Horizontal dashed lines : 95\% confidence levels for Pearson's correlation.

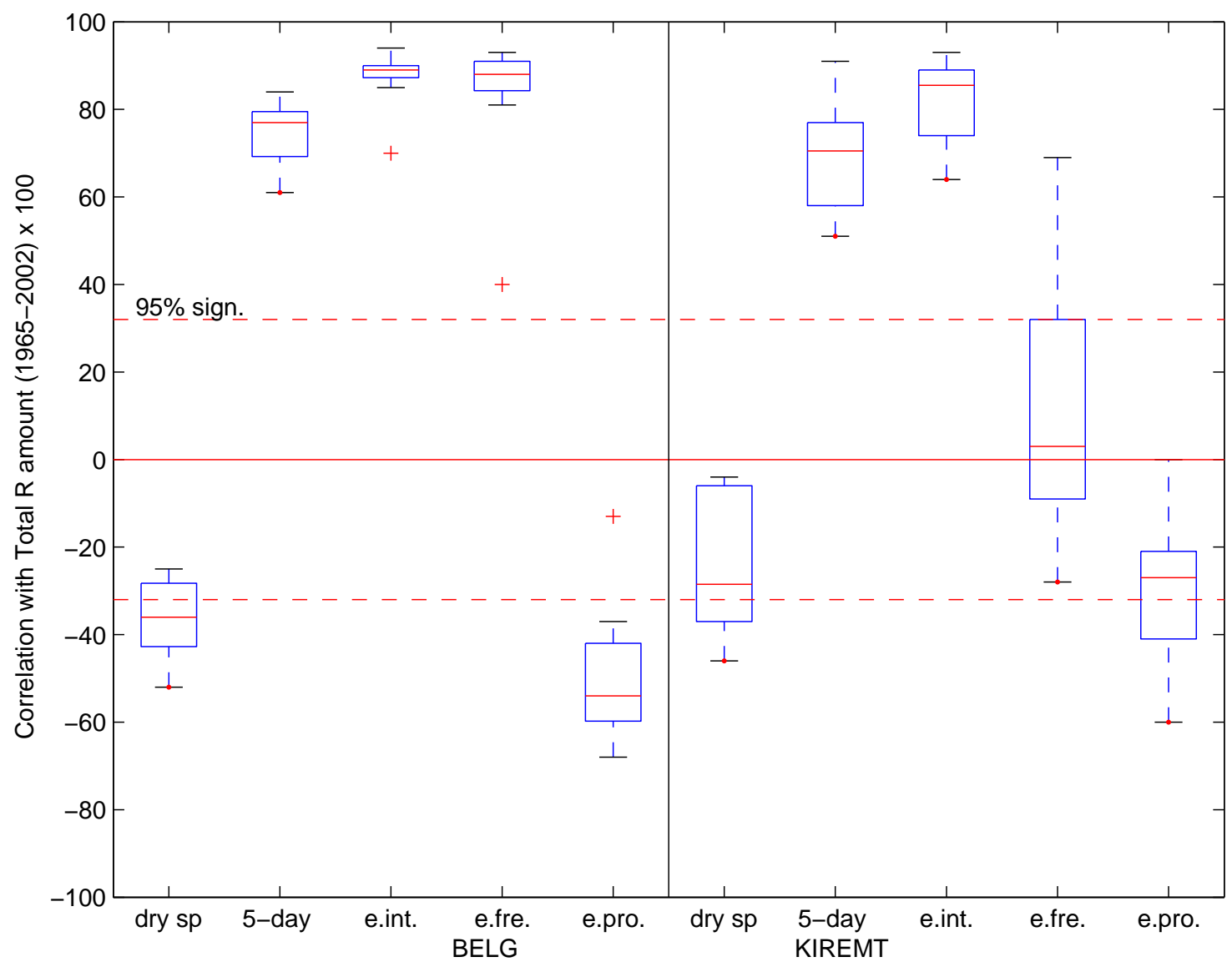

